\title{
Microstructural investigation of the nodular corrosion of 304NG stainless steel in supercritical water
}

\author{
Donghai Du ${ }^{1,2}$, Kai Chen ${ }^{1}$, Lefu Zhang ${ }^{1}$, Zhao Shen ${ }^{3 *}$, \\ 1- School of Nuclear Science and Engineering, Shanghai Jiao Tong University, Shanghai 200240, P. R. China \\ 2- Nuclear Engineering and Radiological Sciences, University of Michigan, Ann Arbor, MI 48109, USA, \\ 3- Department of Materials, University of Oxford, Parks Road, OX1 3PH, Oxford, UK \\ Zhao Shen, E-mail: zhao.shen@materials.ox.ac.uk
}

\begin{abstract}
$304 \mathrm{NG}$ stainless steel was exposed to deaerated $600{ }^{\circ} \mathrm{C}$ supercritical water (SCW) for $300 \mathrm{~h}$. The thin Cr-rich oxide film and corrosion nodules were characterized in detail by cutting edge techniques. The results show that the formation of $\mathrm{MnCr}_{2} \mathrm{O}_{4}$ is an important factor that deteriorates the protectiveness of the Cr-rich thin oxide film. Reaction zones ahead of the inner oxide are observed. The reaction zones are composed of oxide particles and remaining metal, indicating the occurrence of internal oxidation. The internal oxidation controls the further corrosion after the breakdown of Cr-rich thin oxide film, and subsequently the generation of corrosion nodules.
\end{abstract}

Keywords: supercritical water; nodular corrosion; 304NG stainless steel; $\mathrm{MnCr}_{2} \mathrm{O}_{4}$; internal oxidation

\section{Introduction}

Supercritical water reactor (SCWR) inspired by the supercritical fossil plant has been an attractive advanced Generation IV nuclear reactor concept. The SCWR has compacter structure design and higher thermal efficiency compared to the state-of-the-art light water reactors (LWRs) [1, 2]. The thickness of fuel cladding used in the SCWR was significantly reduced to $0.5-0.6 \mathrm{~mm}$, which arises a great concern of the performance of cladding materials in Supercritical water (SCW). Because the thin wall does not provide much margin for corrosion [2].

The austenitic stainless steel 304 that has a low neutron capture cross-section, negligible weight gain rate, and good mechanical properties. Therfore, it has been a promising candidate material for fuel cladding in SCWR [3]. Its corrosion behavior in SCW and water vapor has been widely studied [3-20]. Previous results showed that 304 stainless steel has good corrosion resistance in SCW under $550{ }^{\circ} \mathrm{C}$, however, a substantial increase of corrosion rate appeard above this temperature. When the mateterial was exposure in SCW at these temperatures nodular corrosion appeared on the surface due to the breakdown of thin protective oxide film that formed at early stage $[3,5,6,12,18]$. Serval models have been proposed to elucidate the mechanism of the breakdown of protective oxide films, including Cr volatilization [4, 19], hydrogen absorption [21, 22] and mechanical fracture [23]. However, the 
nano-scale microstructural evolution of oxide films in SCW, which is crucial for the interpretation of the breakdown of oxide films, is still rare. Jonsson et al. [9] reported that the volatilization of $\mathrm{Cr}_{2} \mathrm{O}_{3}$ at low oxygen activities is negligible, therefore, there should be other factors that can affect the breakdown of oxide films but yet to be verified. The present work is designed to study the microstructural evolution of oxide film in 304NG at the early stage in argon deaerated SCW. With the cutting-edge characterization techniques, we expect to get a clearer picture of the corrosion process of this material and pave the way to efficiently develop more corrosion-resistant materials.

\section{Experimental}

Commercial $304 \mathrm{NG}$ with chemical composition of $0.018 \mathrm{C}, 0.58 \mathrm{Si}, 1.21 \mathrm{Mn}, 0.007 \mathrm{~S}, 0.018 \mathrm{P}$, $19.4 \mathrm{Cr}, 69.23 \mathrm{Fe}, 9.35 \mathrm{Ni}, 0.062 \mathrm{Cu}, 0.028 \mathrm{Co}, 0.089 \mathrm{~N}, \leq 0.001 \mathrm{~B}$ (in wt.\%) was machined into coupons with dimensions of $40 \times 20 \times 2 \mathrm{~mm}^{3}$. Each sample has a drilling hole that is used for placing in the autocalve. The surface of the sample was polished with 180\#, 400\#, 800\#, 1200\#, 2000\# sandpaper and finally fine-polished with $1 \mu \mathrm{m}$ alumina paste. Then the samples were cleaned in acetone and ethanol using ultrasonic agitation. The drilling holes in samples were penetrated by a nickel-based string that was fastened to two pillars. To avoid the contact of samples between each other the samples were insulated by zirconium dioxide.

The samples were exposed to argon deaerated SCW at $600^{\circ} \mathrm{C}, 25 \mathrm{MPa}$ for $300 \mathrm{~h}$ in a nickel-based alloy autoclave equipped with a circulation loop, as reported in [24]. Water flow ( $\sim 50 \mathrm{~mL} / \mathrm{min})$ and pressure were maintained with a MiltonRoy high-pressure pump, the pressure was adjusted with a TESCOM pressure regulator. The temperature was controlled by three heating bands on the autoclave and was monitored by a thermocouple in the autoclave at the specimen height. The conductivity of the inlet water fed to the autoclave was controlled below $0.1 \mu \mathrm{S} / \mathrm{cm}$ and high-purity argon was bubbled for 24 hours before heating up to remove the oxygen in the circulation loop, thoroughly. After exposure, the system was cooled down to room temperature and the samples were removed from the autoclave to conduct microanalysis.

A dual-beam Zeiss Nvision 40 scanning electron microscope (SEM) equipped with a focused ion beam (FIB) was used to prepare Transmission electron microscope (TEM) foils. A Zeiss Crossbeam 540 equipped with an electron back-scattered diffraction (EBSD) detector and an energy dispersive spectrometer (EDS) was used to perform EBSD and transmission Kikuchi diffraction (TKD) analysis, and EDS chemical composition analysis, respectively. High-resolution scanning transmission electron microscopy (STEM) JEOL ARM 200F equipped with electron energy loss spectroscopy (EELS) was used to investigate the morphology and chemistry of the oxide films in nanoscale.

\section{Results and discussion}

Fig. 1a shows the metallographic structure and grain orientation of this material, revealing the 
equiaxed grains in the matrix with an average size of $45 \mu \mathrm{m}$. Fig. 1b shows the surface morphology of the sample after exposure in SCW, exhibiting a typical corrosion nodule $(\sim 35 \mu \mathrm{m})$ surrounded by densely packed crystals with an average size of $100-200 \mathrm{~nm}$. The size of the discrete corrosion nodules is reported to increase with exposure time until connecting and eventually covering the entire surface, which deteriorates the protectiveness of the oxide film $[5,6]$. To reveal the microstructure of the corrosion nodule and its formation mechanism, a detailed characterization work has been performed.

(a)
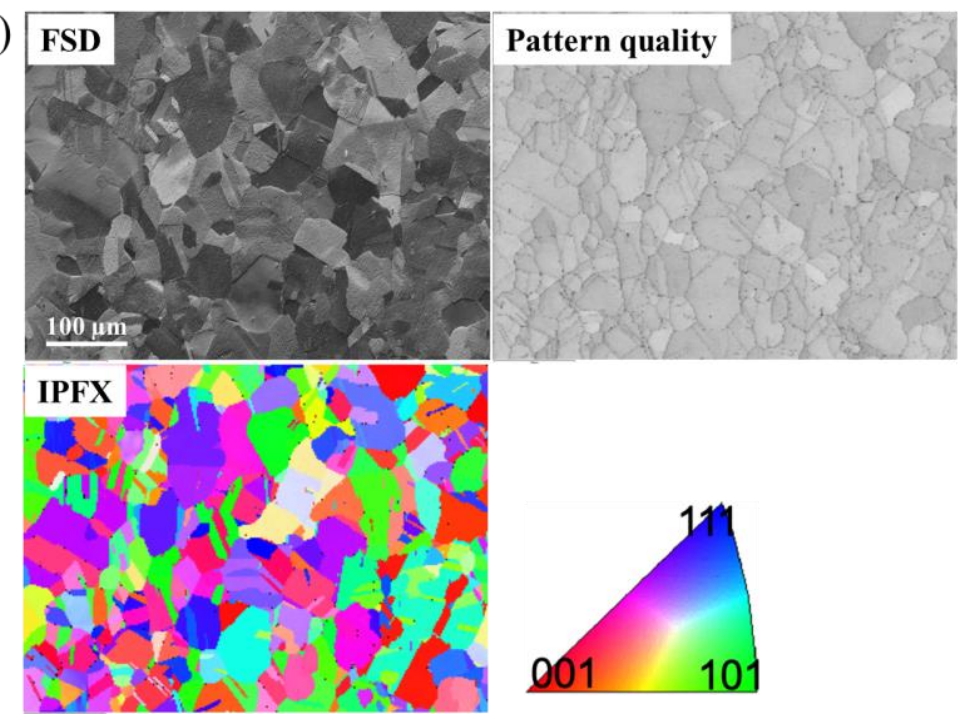

(b)

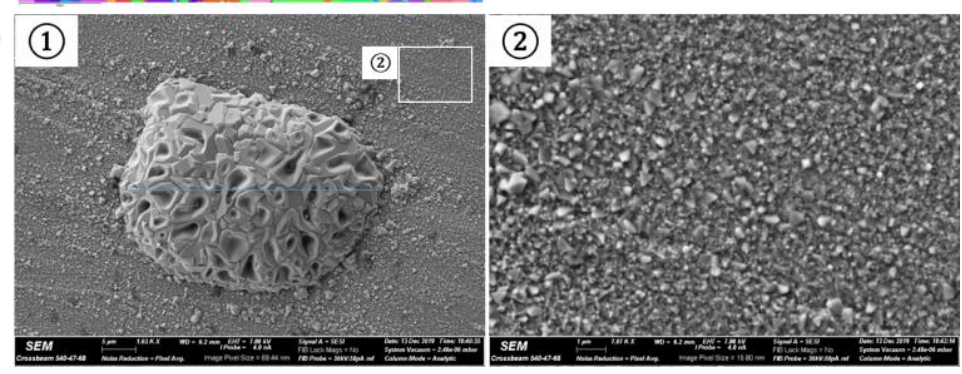

Fig. 1 (a) EBSD analysis of the 304NG matrix, (b) the morphology of 304NG after exposure in SCW for $300 \mathrm{~h}$, a corrosion nodule (1), densely packed crystals (2)).

Fig. 2a shows the cross-section of a corrosion nodule that has a duplex structure, indicated by a red dashed line representing the original specimen surface. The white dashed line represents the inner oxide-matrix interface. Grain morphology in each layer is revealed by the EBSD maps. The outer oxide layer is composed of columnar grains with their long axes parallel to the growth direction. The inner oxide layer has the same orientation with the matrix grains, indicating that the inner oxide has grown by solid-state oxidation due to the inward diffusion of oxygen. However, there is also an unindexed region between the outer and inner oxide layer. This region is probably composed of pores (as shown in Fig. 2b and c) and small size oxide crystal that goes beyond the capability of the traditional EBSD. The microstructure of this region has been further analyzed by TKD and will be presented later.

SEM-EDS analysis was conducted on a corrosion nodule to elucidate the compositional 
characteristics, as shown in Fig. 2b. The qualitative mapping of $\mathrm{O}, \mathrm{Fe}, \mathrm{Cr}$, and $\mathrm{Ni}$ elements are presented in Fig. 2b. No Mn is shown here because its content is too low to be detected by SEM-EDS. The outer oxide is rich in $\mathrm{Fe}$ and is depleted in $\mathrm{Cr}$ and $\mathrm{Ni}$, which is also evidenced by the quantitative EDS line scan (Fig. 2c). As reported by Behnamian et al. [5], the outer oxide is composed of $\mathrm{Fe}_{3} \mathrm{O}_{4}$, while the inner oxide is composed of $\mathrm{FeCr}_{2} \mathrm{O}_{4}$ and $\mathrm{Cr}_{2} \mathrm{O}_{3}$ due to the low oxygen partial pressure. This conclusion also applies to our test as the SCW was deaerated by argon and the dissociation of water was also depressed by high system pressure [25]. The outer $\mathrm{Fe}_{3} \mathrm{O}_{4}$ is defective as evidenced by the pores, indicated by white arrows in Fig. 2b. Sort of Cr enrichment near the outer-inner oxide interface is observed. However, the enrichment of $\mathrm{Cr}$ is not continuous, suggesting that the inner oxide might be not protective, which can be self-proved by the deep crater-like oxide. The enrichment of Ni that below the enriched $\mathrm{Cr}$ is also observed from the EDS mapping. These Ni-rich regions are free of oxygen, indicating that $\mathrm{Ni}$ presents in a metallic state. The reason for this phenomenon is that the oxygen partial pressure is low and nickel-metal is a stable phase under this condition $[7,9,25]$. Nienrichment might be related to the elemental segregation due to the selective oxidation of more reactive elements, such as Cr, Mn, and Fe for this case, under low oxygen partial pressure. Was et al. [20] have reported the absence of nickel in the oxide at the matrix-oxide interface. This phenomenon corresponds well with an oxidation process in which Ni metal is the stable phase.

(a)

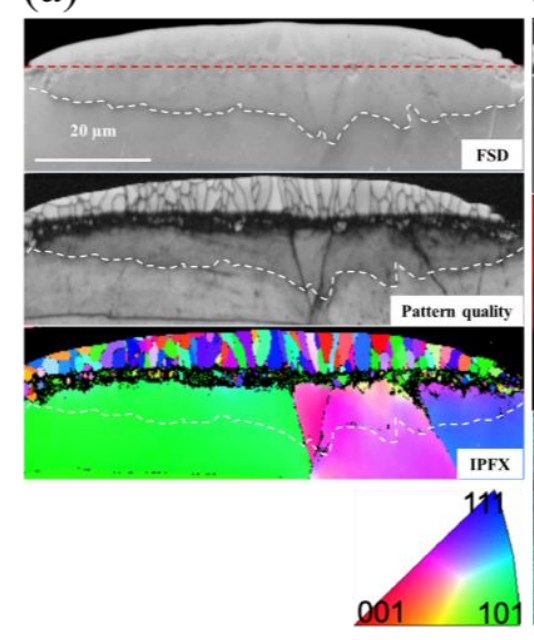

(b)

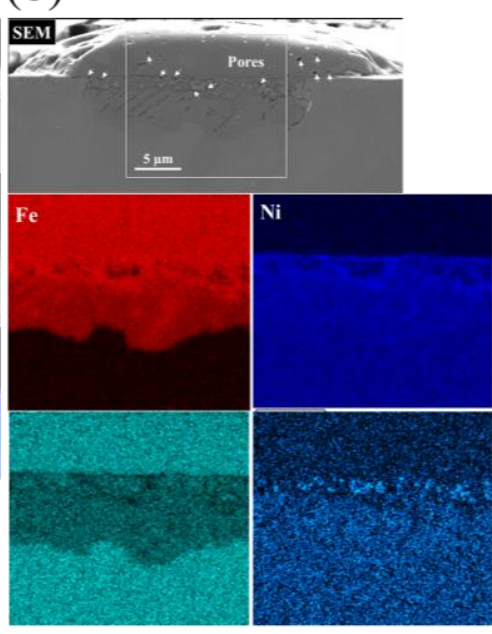

(c)

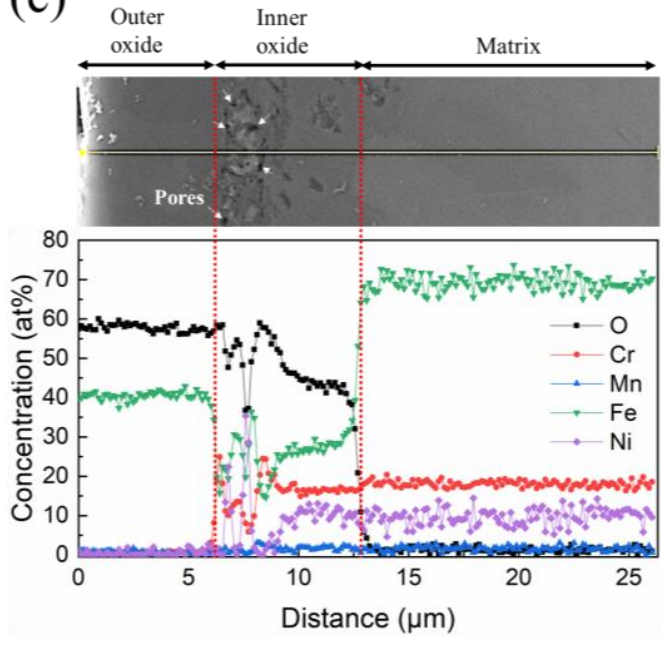

Fig. 2 (a) EBSD analysis of a corrosion nodule, showing large columnar crystals in the outer oxide, (b) SEM-EDS analysis of a corrosion nodule, showing the Fe enrichment in the outer oxide and slight $\mathrm{Ni}$ and $\mathrm{Cr}$ enrichment at the outer-inner oxide interface, (c) quantitative analysis of compositions across a corrosion nodule.

To reveal the breakdown process of the thin oxide film and the subsequent oxidation, FIB was used to prepare TEM samples from the regions with and without corrosion nodules, as shown in Fig. 3. High angle annular dark field (HAADF) imaging and EELS mapping were conducted to show the 
cross-sectional morphology and chemical composition distribution, respectively. EELS mapping shows the signal intensity of major elements, and the brighter contrast corresponds to the higher volume concentration.

Fig. 3a shows the results from a region without corrosion nodules. A thin, adherent oxide film with a thickness of $\sim 200 \mathrm{~nm}$ is observed. The thin oxide film is rich in $\mathrm{Cr}$ and $\mathrm{Mn}$ while depleted in Fe and Ni. The regions enriched in $\mathrm{Cr}$ or $\mathrm{Mn}$ are not fully coincident, suggesting that more than one oxide phase exists in the oxide film. Selective area electron diffraction was conducted on this thin oxide film, confirming the existence of both $\mathrm{Cr}_{2} \mathrm{O}_{3}$ and spinel phases (not shown). The chemical composition in the Cr-rich oxide is measured to be $\sim 39 \% \mathrm{Cr}, \sim 60 \% \mathrm{O}$, and $\sim 1 \% \mathrm{Mn}$, which is likely to be $\mathrm{Cr}_{2} \mathrm{O}_{3}$. The chemical composition in the Mn-rich oxide is measured to be $\sim 24 \% \mathrm{Cr}, \sim 58 \% \mathrm{O}$, and $\sim 18 \% \mathrm{Mn}$, which is likely to be $\mathrm{MnCr}_{2} \mathrm{O}_{4}$ with a spinel structure. Mn has a high diffusion coefficient in $\mathrm{Cr}_{2} \mathrm{O}_{3}$. $\mathrm{Mn}$ is also a strong spinel-forming element that can promote the formation of $\mathrm{MnCr}_{2} \mathrm{O}_{4}$ in a hightemperature environment after further oxidation [26, 27]. With the increase of exposure time, the $\mathrm{Cr}_{2} \mathrm{O}_{3}$ in the oxide film is expected to be partially or fully replaced by $\mathrm{MnCr}_{2} \mathrm{O}_{4}$. This process could be partially attributed to the formation of volatile Cr-bearing specie $\mathrm{CrO}_{2}(\mathrm{OH})_{2}$ that consumes $\mathrm{Cr}$ supplemented from the matrix. The consumsion of $\mathrm{Cr}$ prevents the oxide film from healing [4], though the volatilization rate of $\mathrm{Cr}_{2} \mathrm{O}_{3}$ is not as significant as in oxygenated $\mathrm{SCW}$. Compared to $\mathrm{Cr}_{2} \mathrm{O}_{3}$, the protectiveness of $\mathrm{MnCr}_{2} \mathrm{O}_{4}$ is inferior. Besides, due to the co-existence of $\mathrm{Cr}_{2} \mathrm{O}_{3}$ and $\mathrm{MnCr}_{2} \mathrm{O}_{4}$, the elemental diffusion through the oxide film will be further enhanced along the boundaries of the two different phases.

Fig. $3 \mathrm{~b}$ shows the characterization results from a corrosion nodule. Two distinct layers are observed: 1) outer oxide consisting of almost pure iron oxide $\left(\mathrm{Fe}_{3} \mathrm{O}_{4}\right)$, 2) inner oxide consisting of an oxidized nano-grain layer and a reaction zone. As shown in Fig. 3b, the Cr- and Mn-rich zones are coincident in the inner oxide and reaction zones. Further selective area electron diffraction analysis proves that the Cr- and Mn-rich oxide has a spinel structure (not shown), which is likely to be $\mathrm{MnCr}_{2} \mathrm{O}_{4}$. The chemical composition analysis shows that except for $\mathrm{Cr}$ and $\mathrm{Mn}$, a certain amount of Fe is also detected in the $\mathrm{Cr}$ - and $\mathrm{Mn}$-rich oxide. Since $\mathrm{FeCr}_{2} \mathrm{O}_{4}$ can also form under the experimental condition according to the thermodynamic properties of the FeCrNi-O system [10]. The oxides in the inner oxide can be described as $(\mathrm{Fe}, \mathrm{Mn}) \mathrm{Cr}_{2} \mathrm{O}_{4}$, which is consistent to the results reported in the references [13, 28]. Ni-rich regions are free of oxygen, which is in agreement with the SEM-EDS result in this paper. Fig.

Fig. $3 \mathrm{c}$ shows the microstructure and chemical composition around the reaction zone-matrix interface at a higher magnification. The reaction zone consists of a mixture of oxide and remaining $\mathrm{Fe} / \mathrm{Ni}$ metal, displaying the feature of internal oxidation. The oxide particles in the reaction zone have 
an average size of $\sim 100 \mathrm{~nm}$, showing clearly the enrichment of $\mathrm{Fe}, \mathrm{Cr}$, and $\mathrm{Mn}$ which indicates the formation of $(\mathrm{Fe}, \mathrm{Mn}) \mathrm{Cr}_{2} \mathrm{O}_{4}$. The metal phase in the reaction zone is interconnected, which can work as the inward lattice diffusion paths for oxygen. Also, Jonsson et al. [9] reported that the network oxide-metal interfaces may act as fast diffusion channels, which could further enhance the internal oxidation.

(a)

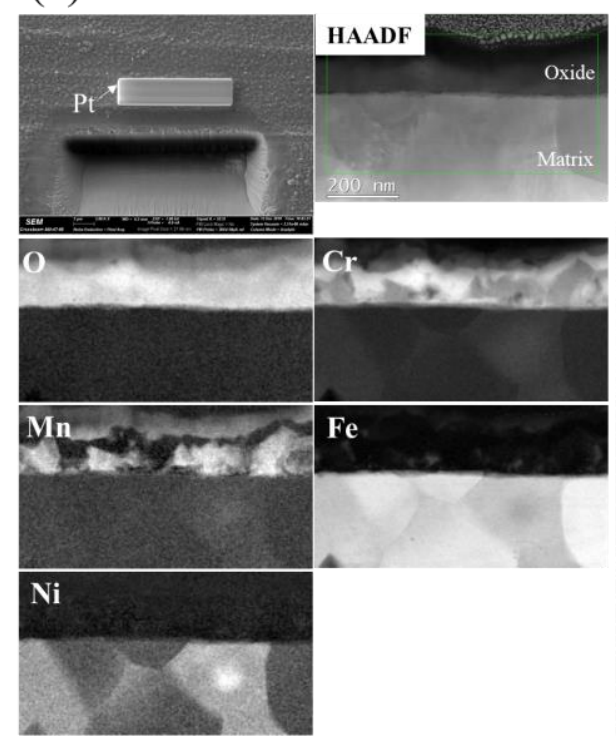

(b)

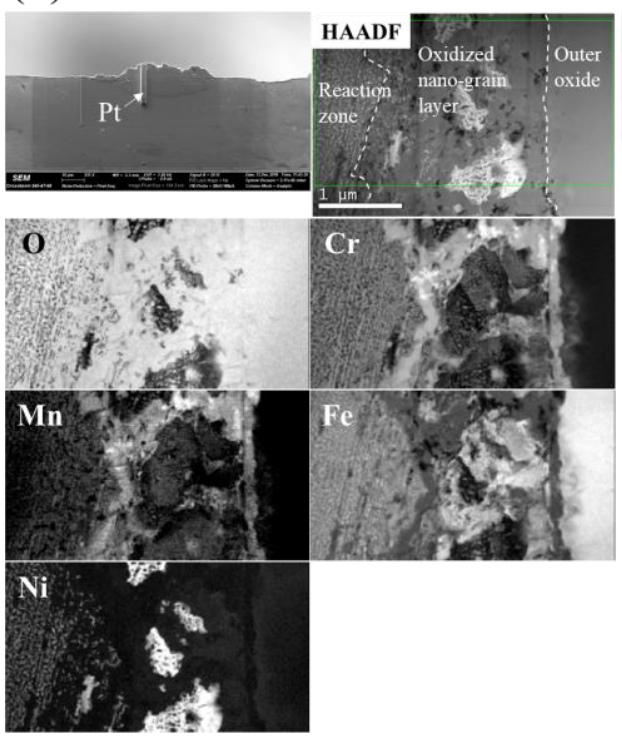

(c)

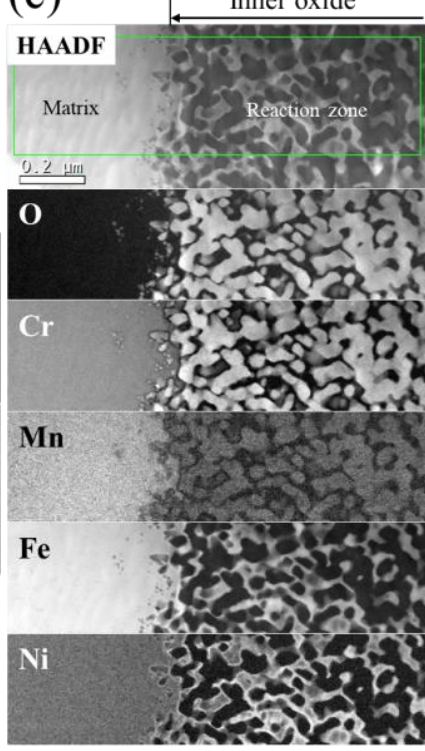

Fig. 3 TEM and EELS mapping of the thin oxide film (a) and a corrosion nodule (b, c). The thin oxide film is rich in $\mathrm{Cr}$ and $\mathrm{Mn}$ (a). The inner oxide of a corrosion nodule has a complex composition and microstructure (b). There is a reaction zone that consists of oxide particles and remaining Fe/Ni metal at the interface of inner oxide and matrix (c).

To further investigate the crystallography of the oxide phase, TKD analysis was conducted on the thin and nodular oxide films (Fig. 4). Fig. 4a shows pattern quality and orientation of oxide phases and metal matrix. The oxide phases show full crystallization with an average size of less than $100 \mathrm{~nm}$. Nano-sized grains in the matrix are also observed. The formation of a nano-grain layer at the surface is very similar to the results reported by Shen et al. [29], and the authors attribute the formation of this layer to the prior mechanical polishing. Nano-grains at the surface can increase the corrosion resistance of this material and prolong the time before the formation of nodules. This is because the abundant grain boundaries can act as short-circuits for the diffusion of self-healing element $(\mathrm{Cr})$, facilitating the formation of a more protective oxide film $[14,30]$. Hence, the protectiveness of the surface oxide film can be affected by the nano-grain layer. However, according to the work conducted by Shen et al. [29] and Chang et al. [31], the microstructure and thickness of the mechanical polishing-induced nano-grain layer have been proved to be not uniform. As a result, the protectiveness of the early-stage thin oxide film varies from region to region. Likely, the oxide nodules will then tentatively nucleates at the region 
where the early-stage thin oxide film has the lowest protectiveness, as shown in Fig. 4b. There are also many unindexed regions in the inner oxide, showing black in both the pattern quality image and orientation map (Fig. 4b). These regions are probably composed of pores or voids, resulting from the coalesce of vacancies. This might be the reason for the spallation of oxide film after long exposure in SCW environment.
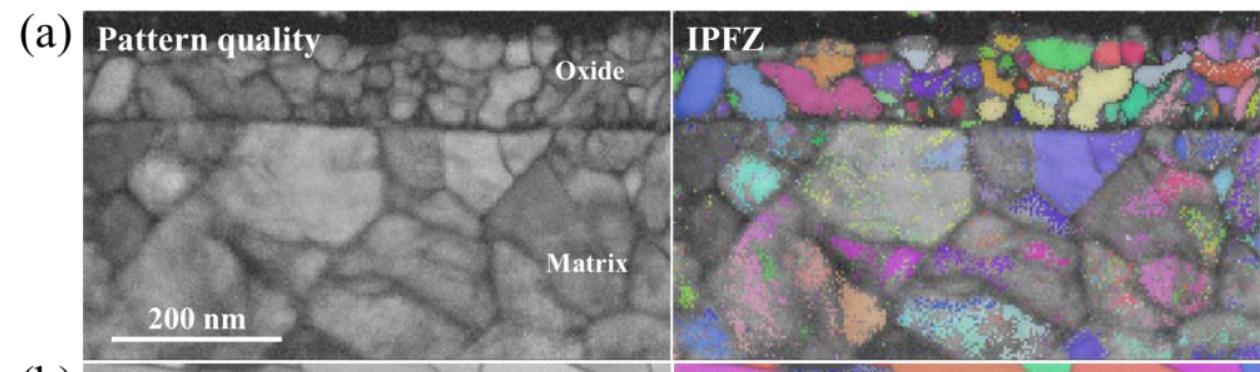

(b)
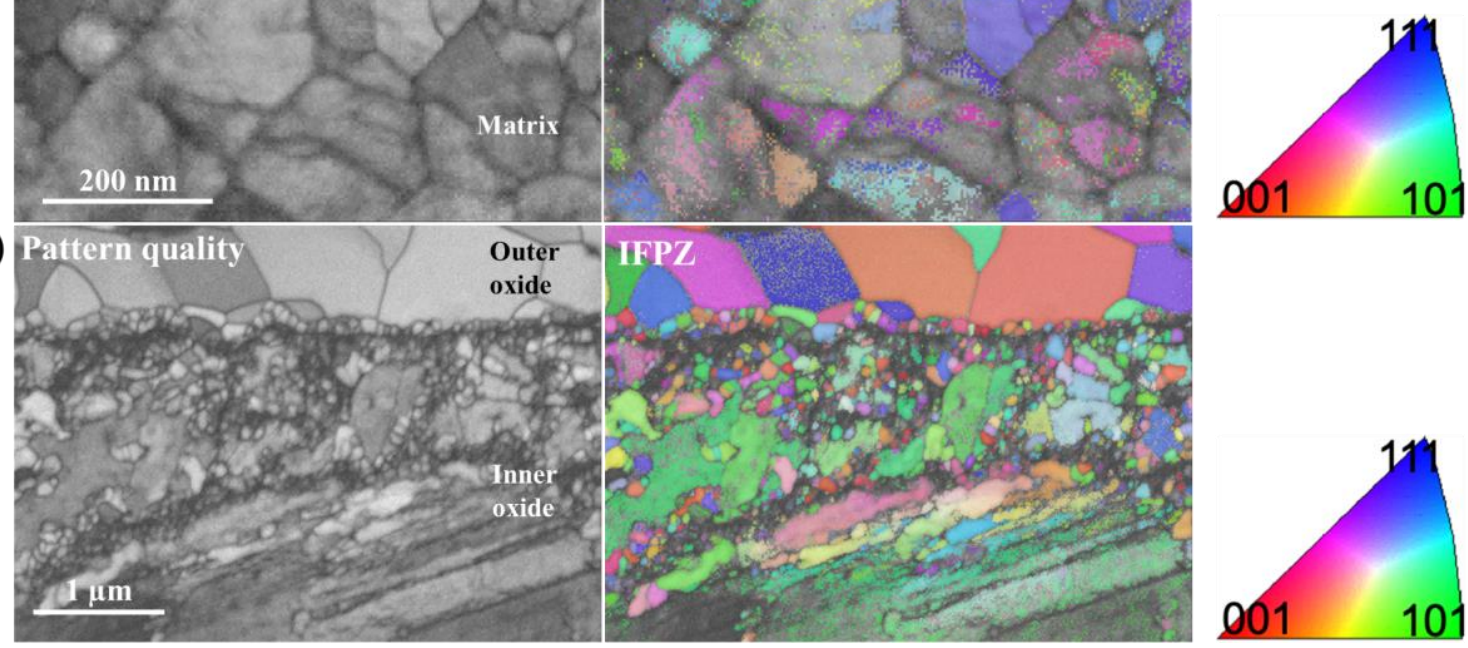

Fig. 4 TKD analysis of the thin oxide film (a) and corrosion nodule (b).

According to the characterization results and discussion above, a mechanism for the formation of corrosion nodules in deaerated SCW has been established. Initially, continuous $\mathrm{Cr}_{2} \mathrm{O}_{3}$ oxide film forms on the surface of the sample after exposure in SCW, which can prevent the matrix from further corrosion. However, with the increase of exposure time, the outward diffusion of $\mathrm{Mn}$ can react with $\mathrm{Cr}_{2} \mathrm{O}_{3}$, forming $\mathrm{MnCr}_{2} \mathrm{O}_{4}$ spinel by the following reaction: $2 \mathrm{Cr}_{2} \mathrm{O}_{3}+2 \mathrm{Mn}+\mathrm{O}_{2}=2 \mathrm{MnCr}_{2} \mathrm{O}_{4}$. The $\mathrm{MnCr}_{2} \mathrm{O}_{4}$ deteriorates the protectiveness of oxide film due to its less protective property than $\mathrm{Cr}_{2} \mathrm{O}_{3}$. In addition, the formation of $\mathrm{MnCr}_{2} \mathrm{O}_{4}$ will inevitably introduce a large number of phase boundaries, which could work as fast diffusion channels and further reduce the protectiveness of the thin oxide film..-Meanwhile, $\mathrm{Cr}_{2} \mathrm{O}_{3}$-also vaporizes by reacting with SCW forming $\mathrm{CrO}_{2}(\mathrm{OH})_{2}$-gas, which consumes Cr supplemented from the matrix and prevents the oxide film from self healing. The nanograin layer formed during mechanical polishing is beneficial to the corrosion resistance due to the increased grain boundary density. However, the nano-grain layer is non-uniformity. Thus, the continuity of $\mathrm{Cr}_{2} \mathrm{O}_{3}$ film in regions where fewer nano-grains exist will be disturbed earlier than other regions. As a result, protectiveness of the oxide film at these regions will loss or be damaged at least. The outward diffusion of Fe cations as well as the inward diffusion of oxygen increases significantly, forming outward-growing corrosion nodule and inward-growing crater-like oxide, respectively. A 
reaction zone that consisted of network-like oxide particles and remaining Fe/Ni metal also forms in the crater-like oxide due to the severe internal oxidation. The diffusion resistance will increase with the growth of the outer and inner oxide layers. Thereafter, the surface oxide will develop laterally until the discrete oxide nodules are connected, generating a uniform duplex surface oxide film.

\section{Conclusions}

From this study, the following conclusions are drawn:

- The formation of $\mathrm{MnCr}_{2} \mathrm{O}_{4}$ is a very important factor that deteriorates the protectiveness of oxide film, which could accelerate the oxidation process and the generation of corrosion nodules. Therefore, the content of $\mathrm{Mn}$ in the material should be carefully considered when the new alloys were designed.

- The oxide film formed above the nano-grain layer has relatively better corrosion resistance in SCW due to the abundant grain boundaries that provide short passes for the diffusion of $\mathrm{Cr}$ supplied from the matrix.

- Internal oxidation occurs and then controls the further corrosion after the breakdown of thin protective oxide film, and subsequently the generation of corrosion nodules.

\section{Declaration of Competing Interest}

We declare that we do not have any commercial or associative interest that represents a conflict of interest in connection with the work submitted.

\section{Acknowledgments}

This work was supported by the National Key Research and Development Program of China [YS2018YFE010246]. The EPSRC (EP/K040375/1, EP/N010868/1 and EP/R009392/1) grants are also acknowledged for funding this research. The authors would like to thank Professor Sergio LozanoPerez for useful discussions.

\section{Data availability}

The raw unpublished supporting data are available upon request. 


\section{References}

[1] T.R. Allen, K. Sridharan, L. Tan, W.E. Windes, J.I. Cole, D.C. Crawford, G.S. Was. Materials challenges for generation IV nuclear energy systems. NUCL TECHNOL. 162 (2008), 342-357.

[2] G.S. Was, P. Ampornrat, G. Gupta, S. Teysseyre, E.A. West, T.R. Allen, K. Sridharan, L. Tan, Y. Chen, X. Ren, C. Pister. Corrosion and stress corrosion cracking in supercritical water. J NUCL MATER. 371 (2007), 176-201.

[3] L. Zhang, Y. Bao, R. Tang. Selection and corrosion evaluation tests of candidate SCWR fuel cladding materials. NUCL ENG DES. 249 (2012), 180-187.

[4] H. Asteman, J.E. Svensson, L.G. Johansson, M. Norell. Indication of chromium oxide hydroxide evaporation during oxidation of 304L at $873 \mathrm{~K}$ in the presence of 10\% water vapor. OXID MET. 52 (1999), 95-111.

[5] Y. Behnamian, A. Mostafaei, A. Kohandehghan, B.S. Amirkhiz, R. Zahiri, W. Zheng, D. Guzonas, M. Chmielus, W. Chen, J.L. Luo. A comparative study on the oxidation of austenitic alloys 304 and 304-oxide dispersion strengthened steel in supercritical water at $650{ }^{\circ} \mathrm{C}$. The Journal of Supercritical Fluids. 119 (2017), 245-260.

[6] M. Halvarsson, J.E. Tang, H. Asteman, J.E. Svensson, L.G. Johansson. Microstructural investigation of the breakdown of the protective oxide scale on a 304 steel in the presence of oxygen and water vapour at $600^{\circ} \mathrm{C}$. CORROS SCI. 48 (2006), 2014-2035.

[7] H. Hooshyar, T. Jonsson, J. Hall, J.E. Svensson, L.G. Johansson, J. Liske. The effect of $\mathrm{H}_{2}$ and $\mathrm{H}_{2} \mathrm{O}$ on the oxidation of 304L-stainless steel at $600{ }^{\circ} \mathrm{C}$ : general behaviour (Part I). OXID MET. 85 (2016), 321-342.

[8] S. Bsat, B. Xiao, X. Huang, S. Penttilä. Oxidation behaviour of alloys $800 \mathrm{H}, 3033$ and 304 in high-temperature supercritical water. OXID MET. 89 (2018), 151-163.

[9] T. Jonsson, S. Karlsson, H. Hooshyar, M. Sattari, J. Liske, J.E. Svensson, L.G. Johansson. Oxidation after breakdown of the chromium-rich scale on stainless steels at high temperature: internal oxidation. OXID MET. 85 (2016), 509536.

[10] T. Jonsson, H. Larsson, S. Karlsson, H. Hooshyar, M. Sattari, J. Liske, J.E. Svensson, L.G. Johansson. Hightemperature oxidation of $\mathrm{FeCr}(\mathrm{Ni})$ alloys: the behaviour after breakaway. OXID MET. 87 (2017), 333-341.

[11] H. Li, Q. Cao, Z. Zhu. Oxidation behaviour of Super 304H stainless steel in supercritical water. Corrosion Engineering, Science and Technology. 53 (2018), 293-301.

[12] Y. Li, S. Wang, P. Sun, Z. Tong, D. Xu, Y. Guo, J. Yang. Early oxidation of Super304H stainless steel and its scales stability in supercritical water environments. INT J HYDROGEN ENERG. 41 (2016), 15764-15771.

[13] V. Parry, A. Col, C. Pascal. Beneficial effect of cold-working on high temperature oxidation resistance of austenitic stainless steel. CORROS SCI. 160 (2019), 108149.

[14] X. Peng, J. Yan, Y. Zhou, F. Wang. Effect of grain refinement on the resistance of 304 stainless steel to breakaway oxidation in wet air. ACTA MATER. 53 (2005), 5079-5088.

[15] J.C. Rosser, M.I. Bass, C. Cooper, T. Lant, P.D. Brown, B.J. Connolly, H.E. Evans. Steam oxidation of Super 304H and shot-peened Super 304H. MATER HIGH TEMP. 29 (2012), 95-106.

[16] Y. Zengwu, F. Min, W. Xuegang, L. Xingeng. Effect of shot peening on the oxidation resistance of TP304H and HR3C steels in water vapor. OXID MET. 77 (2012), 17-26.

[17] N. Zhang, Z. Zhu, G. Yue, D. Jiang, H. Xu. The oxidation behaviour of an austenitic steel in deaerated supercritical water at 600-700 ${ }^{\circ} \mathrm{C}$. MATER CHARACT. 132 (2017), 119-125.

[18] D. Rodriguez, A. Merwin, D. Chidambaram. On the oxidation of stainless steel alloy 304 in subcritical and supercritical water. J NUCL MATER. 452 (2014), 440-445.

[19] D.J. Young, B.A. Pint. Chromium volatilization rates from $\mathrm{Cr}_{2} \mathrm{O}_{3}$ scales into flowing gases containing water vapor. OXID MET. 66 (2006), 137-153.

[20] G.S. Was, S. Teysseyre, Z. Jiao. Corrosion of austenitic alloys in supercritical water. (2006). 
[21] S. Henry, A. Galerie, L. Antoni. Abnormal oxidation of stabilized ferritic stainless steels in water vapor. In Materials science forum. Trans Tech Publications Ltd2001. pp. 353-360.

[22] H. Nickel, Y. Wouters, M. Thiele, Q.W. J. The effect of water vapor on the oxidation behavior of $9 \% \mathrm{Cr}$ steels in simulated combustion gases. Fresenius' journal of analytical chemistry. 361 (1998), 540-544.

[23] S. Jianian, Z. Longjiang, L. Tiefan. High-temperature oxidation of Fe-Cr alloys in wet oxygen. OXID MET. 48 (1997), 347-356.

[24] Z. Shen, L. Zhang, R. Tang, Q. Zhang. The effect of temperature on the SSRT behavior of austenitic stainless steels in SCW. J NUCL MATER. 454 (2014), 274-282.

[25] J. Yuan, X. Wu, W. Wang, S. Zhu, F. Wang. The effect of surface finish on the scaling behavior of stainless steel in steam and supercritical water. OXID MET. 79 (2013), 541-551.

[26] R.E. Lobnig, H.P. Schmidt, K. Hennesen, H.J. Grabke. Diffusion of cations in chromia layers grown on iron-base alloys. OXID MET. 37 (1992), 81-93.

[27] Z. Dong, M. Li, Y. Behnamian, J.L. Luo, W. Chen, B.S. Amirkhiz, P. Liu, X. Pang, J. Li, W. Zheng, D. Guzonas, C. Xia. Effects of $\mathrm{Si}, \mathrm{Mn}$ on the corrosion behavior of ferritic-martensitic steels in supercritical water (SCW) environments. CORROS SCI (2020), 108432.

[28] M.A. L, Y.D. J. The Oxidation of Iron-Chromium-Manganese Alloys at 900. OXID MET. 36 (1991), $157-174$.

[29] Z. Shen, K. Chen, D. Tweddle, G. He, K. Arioka, S. Lozano-Perez. Characterization of the crack initiation and propagation in Alloy 600 with a cold-worked surface. CORROS SCI. 152 (2019), 82-92.

[30] X. Ren, K. Sridharan, T.R. Allen. Effect of grain refinement on corrosion of ferritic-martensitic steels in supercritical water environment. Materials and Corrosion. 61 (2010), 748-755.

[31] L. Chang, L. Volpe, Y.L. Wang, M.G. Burke, A. Maurotto, D. Tice, S. Lozano-Perez, F. Scenini. Effect of machining on stress corrosion crack initiation in warm-forged type $304 \mathrm{~L}$ stainless steel in high temperature water. ACTA MATER. 165 (2019), 203-214. 